\title{
Kripto Paralar ve Blok Zinciri: Turizm Sektörü Üzerine Bir Değerlendirme
}

\section{Crypto Coins And Blockchain: An Evaluation On The Tourism Sector}

\author{
Nihan GARİPAĞAOĞLU UĞUR, İstanbul Medeniyet Üniversitesi, Türkiye, nihan.g@ hotmail.com \\ Orcid No: 0000-0003-2390-6940 \\ Ender DEMİR, İstanbul Medeniyet Üniversitesi, Türkiye, ender.demir@ medeniyet.edu.tr \\ Orcid No: 0000-0003-4034-269X
}

\begin{abstract}
Öz: Çalışmanın amacı turizm sektöründe kripto para ve blok zinciri teknolojisinin kullanım alanlarının tanıtılmasıdır. Çalışma literatür incelemesiyle yapılmıştır. Bu amaç doğrultusunda blok zinciri kripto paralar hakkında bilgi verilmiş, Bitcoin ve altcoinler tanıtılmıştır. Mevcut durumda blok zinciri teknolojisinin kullanım alanları özetlenmiştir. Ayrıca turizmdeki kullanımı ve gelecekte edinebileceği yer hakkında bilgi verilmiştir. Bu çallşmada, blok zinciri ve Bitcoin 'in turizm sektöründeki konukların ve yiyeceklerin takibi, puanlama sistemleri, dijital kimlik, para transferleri gibi kullanımları detayl bir şekilde açıklanmıştır. Konaklama işletmeleri ve havayollarının yanı sıra seyahat acentalarının da blok zinciri platformu üzerinden yapabilecekleri işlemler hakkında bilgilendirme yapılmıştır.
\end{abstract}

Anahtar Kelimeler: Bitcoin, Altcoin, Blok Zinciri, Turizm

JEL Siniflandirması: E42, L83, Z30, Z33, Z38

\begin{abstract}
The purpose of study is to introduce about criptocurrency, Bitcoin and blockchain technology and how to use in tourism sector. Study includes literature review. For this purpose, Bitcoin and altcoins have been introduced. The use of blockchain technology is explained. The sample of the study is the tourism enterprises which are adapting to the blockchain system in the tourism sector. Accommodation companies tracking guests and tracking food, scoring systems, digital identity and airlines, as well as travel agencies on the blockchain platform can be done about the information was made. The study was terminated with suggestions for use of blockchain.
\end{abstract}

Keywords: Bitcoin, Altcoins, Blockchain, Tourism

JEL Classification: $\quad$ E42, L83, Z30, Z33, Z38

\section{Giriş}

Gelişen teknoloji internetin ve mobil cihazların yaygın kullanılmasına sebebiyet vermiştir. İnsanların yeni arayışlar içerisinde olması, hızlı ve güvenli işlem yapabilme istekleri doğrultusunda kripto para birimleri ortaya çıkmıştır. Kriptografik $^{1}$ olarak şifrelenmiş olan kripto paralar, güvenli işlem yapmaya olanak sağlayan; dijital ve sanal paralardır (Graydon 2014). Bu kripto paralar içerisinde en bilinenlerinden biri de "Bitcoin"dir. Satoshi Nakamoto tarafindan 2009 y1lında yaratılan Bitcoin, kişiler arası direk kripto para transferi yapmaya olanak sağlar (B. CoinTurk 2018). 2017 yılında 20 bin dolarlık tepe noktasını gördükten sonra, "ayı sezonuna" girerek düşüşe geçen Bitcoin 2019 yılının ikinci çeyreğinde "boğa sezonuna" geçerek, tekrar yükselişe geçmiştir (KoinMedya, 2019). "Ayı sezonu" genel anlamda, fiyatların olumsuz olarak seyrettiği ve daha çok düşüse geçebileceği savunulan piyasa trendidir. "Boğa sezonu" ise daha iyimser bir yaklaşım sergiler ve fiyatların daha da yükseleceği bir piyasa trendidir (Bilgin 2019). Ekonomistlerinde ilgisini çeken Bitcoin, mevcut ödeme sistemlerinde değişikliğe sebebiyet verebilir. Geleneksel finansal sistemler ve ekonomi ile etkileşim halindedir. Mahdut miktarda üretilmiş olan Bitcoin, herhangi bir merkezi otoriteye bağlı olmadığından dolayı, kimlik bilgilerinin ifşaası mümkün değildir. Para aktarımlarınında işlemin doğrulanması süreci oldukça önemlidir. Bitcoin kullanıcısı isim yada kimlik bilgisi vermeden bir cüzdan oluşturarak, taraflar arasında kripto para aktarımı yapmasını sağlayacak olan blok zinciri (blockchain) yapısına erişim sağlayabilir (Böhme, ve diğerleri 2015). Fiziki karşıllı̆ı bulunmayan Bitcoin'in 2009 yılında kullanıma girmesiyle birlikte, blok zinciri teknolojisi de kullanılmaya başlamıştır. Son yıllarda blok zinciri kullanımı pek çok alanda yaygınlaşmıştır. Turizm sektöründe online acentalar vasıtasıyla, direk olarak müşteri ve tedarikçi arasındaki satış esnasında kullanımı başlamışıır. Bu çalışmanın amacı blok zincirinin turizm sektöründe kullanımına yönelik bilgilendirme yapmaktır.

Blok zinciri 2017 yılından itibaren bankacılık, sağlık, perakende sektöründe kullanılmaya başlanmıştır ve diğer sektörlere göre, turizm en fazla kullanıldığ sektör olmuştur. Süreç olarak blok zinciri teknolojisi, turizmin gelişiminde önemli etkilere sahiptir (Kwok ve Koh 2018).Morgan Stanley tarafindan yapılan, kripto para işlemleriyle ilgili bir araştırmaya göre, en büyük sanal para platformları İngiltere başta olmak üzere, Hong Kong, ABD, Singapur ve Türkiye olarak sıralanmıştır. Bununla birlikte, yine Morgan Stanley tarafindan yapılan açıklamaya göre, en fazla borsa sayısı

\footnotetext{
${ }^{1}$ Kriptografik: bir blok şifreleme algoritması kullanan, şifre kontrol fonksiyonu ile veri bütünlüğünü sağlama düzeneği
} 
İngiltere'de olmasına rağmen, kripto para piyasalarındaki en büyük akış Malta'da olmaktadır. Malta kendisini “blok zinciri” adası olarak pazarlamaktadır. Malta'yı, Belize ve Şeyseller takip etmektedir (Küçük 2018).

$\mathrm{Bu}$ araştırma, Dünya turizminde kullanılan kripto para ve blok zinciri teknolojilerinin, Türk turizminde de kullanılabileceği alanları tanıtmak açısından önemlidir. Araştırma ikincil verilere dayanmaktadır. Literatür incelemesi yapılarak kripto paralar, blok zinciri teknolojisi ve kullanım alanları incelenmiştir.

Yazının birinci bölümünde kripto para kavramı anlatılmıştır. İkinci bölüm itibariyle Bitcoin, altcoin'ler ve kullanımı anlatılmıştır. Sonraki bölümde blok zinciri teknolojisi tanıtılmıştır. Blok zinciri teknolojisinin kullanım alanlarının tanıtımının ardından, turizmde kullanılabileceği alanlar hakkında bilgilendirme yapılmıştır.

Araştırmacılar özellikle küçük adalarda kripto para ticaret hacminin yüksek olduğuna dair çalışmalar yapmışlardır. Malta "blok zinciri” adası haline gelmiştir. Aruba, Barbados, Karayip Adaları, Porta Rico gibi geleneksel finansmanın yetersiz kaldığı ekonomilerde, kripto para birimleri devreye girmiştir.

Blok zinciri teknolojisinin kullanılabileceği turizm ile ilgili alanlar daha önceden yapılan araştırmalarda tespit edilmiştir. Dogru ve diğ., (2018) yapmış olduğu çalışmada uçaktan indiği an itibari ile konukların takibi, otel giriş işlemlerinin yapılması, yiyeceklerin muhteviyatı hakkında; Kowalewski, \& diğ, (2017) sadakat puanları karşılığında Bitcoin verilmesi; Önder \& diğ. (2018) dijital kimliklerin oluşturulması, turizm ürünlerinin satın alınmasında para transferlerinin yapılması, bayilik (frenchise) anlaşmalarında yapılan ödemelerde blok zinciri kullanımı için tavsiyelerde bulunmuşlardır.

Yapmış olduğumuz çalışma ile turizm sektöründe alternatif kullanım için önerilerimiz: konukların sadece otel girişlerinde değil, acenta - araç transfer hizmeti esnasında, yol güzergahı boyunca takip edilmesi ve araçların birden çok işe vaktinde yetişebilmesinin sağlanması; restaurantların malzemelerinin dijital ortamda takibi yapılırken, azalan malzemenin otomatikman tedarikçiye bildirilerek, sipariş edilmesi; havacılık sektöründe kazanılan kripto paranın istenilen bir başka sektörde kullanılabilmesi; acentalar tarafindan yapılan rezervasyonlarda, yolcu bilgilerinin dijital kimlik güvencesi ile saklanabilmesi; acentaların bayilik (franchise) anlaşması yaparken, teminat mektubu yerine kripto para bloke ederek, banka teminat mektuplarının masraf yüklerinin hafifletilebileceği yönündedir.

Online seyahat acentalarının yaygınlaştığı ve aracıların devre dışı bırakılarak maliyetlerin düşürüldüğü, müşteri ile direk iletişime geçilen bu sistem içerisinde blok zinciri ve kripto para birimlerinin daha da yaygınlaşması beklenmektedir.

\section{Kripto Para}

Ekonomide tarih boyunca farklı formlarda olan paranın kullanım şekilleri zaman içerisinde değişmiştir. Değiş tokuş aracı olarak kullanıldığı zamandan beri, deniz kabuğu, boncuk veya altın formlarında kullanılmıştır (Üzzer 2017). Altın paranın yerini, Temmuz 1944'de yapılan Finans Konferansı sonucunda; US Dolarının altına endekslendiği ve diğer paralarında US Dolarına endekslendiği, Bretton Woods sistemi ile kâğıt para kullanımı almıştır (Eğilmez 2018).

Bankalar kredi verme ve risk alma konusunda önde gelen ve ekonomik olarak etkin pozisyonda bulunan kuruluşlardır. Hali hazırda müşterilerin mevduatları için ilk tercihleri olmaları sebebiyle, ödeme sistemine hâkim yapıdadırlar. Bununla birlikte yaşanan finansal krizler ile bankacılık sistemine olan güven sarsılmıştır. Mobil cihazlarda yaygınlaştıkça, bankaların fiziki dağıtım avantajları da azalmıştır (Dietz, ve diğerleri 2016).

Kripto para (şifreli para), kriptografik olarak şifrelenmiş güvenli işlem yapmaya olanak sağlayan, ek sanal para arzıdır. Kripto paralar alternatif olarak sunulmuş dijital ve sanal paralardır (Graydon 2014). Dijital para, elektronik ortamda üretilen ve gelişmiş ülkelerde kullanılan, devletler tarafından kabul gören bir uygulamadır. Kısmi Rezerv Sistemi kullanılarak bankalar tarafından oluşturulur ve \%10'luk kısmı, merkez bankalarında rezerv olarak bulundurulur (Yıldırım 2015). Sanal paralarda dijital paralardır ama karşılığında temsil edilen bir fiziksel gerçeklik yani basılı kâğıt para bulunmamaktadır. Dijital para ise kâğıt parayı temsilen oluşturulmuştur (Çarkacıoğlu 2016).

Gelişen teknoloji ve internetin yaygın kullanımı, cep telefonlarından her an online olarak bağlanabilme özelliklerinin olması, insanların yeni arayışlara yönelmesine sebebiyet vermiş ve kripto para birimleri ortaya çıkmıştır. Bunlardan en bilineni "Bitcoin" olarak adlandırılmıştır. Bitcoin ve benzeri kripto paralar, dijital ve sanal paralarla karıştırılmaktadır. Dijital ve sanal paralar, kendi başlarına birer para birimi değillerdir. Denetlenebilen, kullanıldıkları ülkenin para birimine dayalı birimlerdir. Bitcoin ise merkezi otoritelerce denetlenemeyen, kendi başına bir kripto para birimidir (Rotman 2014).

Kripto para sistemleri genel olarak dolaşımdaki sanal parayı sabitleyebilmek maksadıyla, kripto para üretimini belirli bir miktar ile sınırlar. Fiziki varlığı olan banknot paralar devletlerin güvencesi altındayken, kripto paralara olan güven, sistem kullanıcılarının yanlış yapmayacağı temellidir (Çarkacıoğlu 2016)

\section{Bitcoin}

Bilinen ve en yaygın kullanılan ilk kripto para, 2009 yılında Satoshi Nakamoto tarafından yaratılan Bitcoin olup, "BTC" kısaltması kabul edilmiştir. Bitcoin kişiden kişiye (P2P) direk olarak transfer yapma imkânı sunarak aracıları devreden çıkartır. Bitcoin üretmek için "mining” olarak adlandırılan, madencilik işlemini yapmanız gerekmektedir. Sadece madencilik için üretilmiş makinalar ile büyük Bitcoin tarlalarından elde edilebilir. Bitcoin ile internet üzerinden alışveriş yapılabildiği gibi, kripto para transferleri gerçekleştirilebilir. Bunun yanı sıra aracılar vasıtasıyla, yerel para birimlerine dönüştürülebilir (B. CoinTurk 2018). 
Bitcoin; merkezi olmayan bir ağ etkileşimi olup, fiziki bir karşıllı̆ı olmayan bir kripto para birimidir. Aracı ya da komisyoncuya ihtiyaç duymadan, elektronik para transferi yapılabilir. Transfer esnasında güvenliği sağlayan denetleyicilere yani madencilere çok cüzi bir miktarda, transferin hızına bağlı olarak bir ödeme yapılır. Açık kodla yazıldığından dolayı, herkes aynı zamanda sistemin sahibidir ve offline hesaba kimse müdahale edemez. Madenciler tarafından üretilir. Toplam olarak 21 milyon adet üretilecek şekilde ayarlanmıştır. Bitcoin transfer imzası tek seferliktir. Madenciler tarafından kontrolü sağlandıktan sonra, transfer gerçekleştirilir ve bir kez daha kullanılamaz. Mobil ödeme yapmaya elverişlidir, aracıya ihtiyaç duymaz, her an her yerden kripto para aktarımı masrafsızca yapılabilir, sadece kontrolü yapan denetçilere bir miktar ücret ödenir (B. CoinTurk 2018).

İnternet üzerinden yapılan ticari işlemler ve yapılan transfer işlemlerinin güvenilirliği finansal aracı kurumlar ile sağlanmaktadır. Aracı hizmetlerinin maliyetinin yanı sıra, limitli miktarların transferleri gerçekleştirilebilir ve yapılan işlemlerin geri dönüşümü bulunmaz. Kayıp ve dolandırıcılıkların olma ihtimali, aracıları gerekli kılmaktadır. Güvenliği kriptografik kanıtlara dayalı bir elektronik ödeme sisteminde, taraflar aracıya ihtiyaç duymaksızın kripto para transferini gerçekleştirebilirler. Taraflar arasında, bir finansal kurum aracılı̆ıııdan geçmeksizin online olarak ödeme gerçekleştirilebilmesi için, kişiye özel dijital imza gerekmektedir. En önemli sorun, çifte harcamanın önlenmesidir. A ̆g üzerinden yapılan ve zaman damgası bulunan transfer işlemi, bir zincire bağlandığı takdirde, işlem kayıt altına alınmış olur ve değiştirilemez. İşlemlerin tersine de çevrilebilecek olması, tarafları dolandırıcılıklardan da koruma amaçlıdır. Zincirindeki dijital imzalı elektronik para transfer edilirken, her bir transferi gerçekleştiren kendi imzasını zincirin sonuna ekleyerek, bir sonrakine aktarır. Alacaklı olan kişide işlemin gerçekleştiğini doğrulayabilir. Çifte harcama yapılmasını önlemek amacıyla kontrollerin yapılması ve alacaklı için gönderilen kripto paranın daha önceden harcanmamış olduğunun bilinmesi gereklidir. İlk transfer gerçek kabul edildiğinden, dijital paranın birden fazla kere harcanmasının önlenmesi için tüm işlemlerin sıkı takibi yapılması gerekmektedir (Nakamoto 2008). Aracı kullanmaksızın bunu yapabilmek için, tüm işlemlerin halka açık şekilde gerçekleştirilmesi gerekir (Dai 1998).

Bitcoin hesabı oluşturmak için herhangi bir ücret ödenmez ve merkezi bir güvenlik soruşturması yapılmaz, hatta gerçek isim dahi kullanılması gerekmez. Bitcoin ekonomistlerinde ilgisini çeken, mevcut ödeme sistemlerini dahi bozabilecek bir sanal para birimidir. Her Bitcoin işlemi takip edilir ve yapılan her işlem, katılımcılar tarafından görülebilir. Bitcoin ağında yapılan her yeni işlem, blok içerisine kayıt edilir. Transfer ortak olarak onaylanmadıkça gerçekleşmez ve blok zincirine kayıt edilmez. Madenciler sürekli yeni yapılan transferlerin kontrolü yapmakta olsalar da, işlemler ortalama 10 dakika içerisinde tamamlanır. Madenciler oy birliği ile transferin doğruluğunu onayladıkça, zincire yeni halkalar eklenir. Bazı durumlarda işlem onayı durdurulabilir çünkü bazı madenciler, farklı sonuca ulaşmış olabilir. Ancak altı madencinin onayı olması halinde transfer işlemi kesin kabul edilir. Fikir ayrılığı olması ve yeniden onaylanması, transfer süresini yaklaşık bir saate kadar uzatabilir (Böhme \& diğ., 2015)

Bitcoin alıp satmak veya kullanmak için Cüzdan (wallet) denilen bir program kullanılır. Bankaların hesap kullanımlarından doğan ücretleri, Bitcoin içerisinde yoktur. EFT, havale masrafı, kart ücreti gibi ücretler yansımaz (Çarkacıoğlu 2016). Bitcoin kişisel bilgilerin gizliliği temeline dayanır. Cüzdanlar arası kripto para transferi sağlar, kimlik bilgileri yerine numaralar vardır ve kişisel bilgileri ihtiva etmez. Bununla birlikte, cüzdan numarasının bir başkası tarafindan bilinmesi halinde tüm işlemlerin görülmesi olasılığı bulunur (Antonopoulos 2017).

2009 yılından itibaren tüm Bitcoin transfer işlemleri blok zinciri adıverilen hesap defterlerinde tutulur. Bu zincir defteri dileyen herkes tutabilir ve işlemlerin doğruluğunu kontrol edebilir. Madenciler defter kayıtlarını yazarlar ve güvenilirliği sağlarlar (Çarkacıoğlu 2016).

Bitcoin'e olan ilgi arttıkça, altcoin adı verilen türevleri de ortaya çıkmıştır (Yıldırım 2015). Mevcutta 200'den fazla altcoin bulunmakla birlikte, exchance sitelerinde her zaman bulunamayabilir. Bunun sebebi Pazar paylarının yeterli olmamasından dolayıdır. Altcoin'in üretilme sebebi, madencilik işleminin nispeten daha kolay olmasıdır. Böylece daha düşük zorlukta olan altcoin üretilip, mevcut kura göre Bitcoin’e çevrilebilir (A. CoinTurk 2018).

\section{Altcoin}

Kripto paraların ortaya çıkmasına müteakip üretilen altcoinler arasında devam edenler olduğu gibi, piyasadan kalkan altcoinlerde olmuştur. Çoğu altcoin grubu doldur - boşalt (Pump And Dump) şeklinde oluşturulmuştur. Yaratıcılarının vaatleri sebebiyle popüler olurlar. Bunun yanı sıra ciddi anlamda çalışan LiteCoin, CasinoCoin ve GuldenCoin gibi gruplarda mevcuttur (Prypto 2016). Litecoin, bir merkeze bağlı olmayan açık kaynak kodlu dijital para birimidir. Bitcoin'den farkı, standart donanımlı bilgisayarlarda bile kesintisiz olarak madencilik yapmaya olanak tanımasıdır. Ayrıca yapılan işlemler daha hızlı olarak onaylanır (CoinMedya 2018).

Gulden coin hızlı ve güvenli elektronik para transferi sağlayan bir kripto para birimidir. Değeri kullanıcı sayısına göre artar. Pek çok yerde alışveriş imkânı sağlar, alıcı ve satıcı da asgari işlem ücretine tabi olurlar (Peters 2017).

Ethereum (ETH), tanıtımı kurucusu Vitalik Buterin tarafından Amerika Bitcoin Konferansı esnasında yapılmış olan bir altcoin olmakla birlikte, diğerlerine nazaran daha çok yeniliğe sahip olan bir kripto işletim sistemidir (E. CoinTurk 2018). Akıllı sözleşme (komut dosyası) işlevselliğine sahip, blok tabanlı ve halka açık bilgi işlem platformudur. Ethereum, Bitcoin'den sonra en fazla değere sahip sanal para birimidir (Döviz.com 2019).

CoinMarketCap, (2019) taraından yapılan çalışma en fazla değere sahip kripto paraları sıralamıştır. 
Tablo 1. Pazar Değerine Göre İlk 10 Kripto para

\begin{tabular}{|c|c|c|c|}
\hline Siralama & İsim & Piyasa Değeri & Fiyat \\
\hline 1 & Bitcoin & $\$ 73.493 .348 .585$ & $\$ 4.186,45$ \\
\hline 2 & Ethereum & $\$ 17.262 .599 .296$ & $\$ 164,43$ \\
\hline 3 & XRP & $\$ 13.917 .663 .441$ & $\$ 0,336455$ \\
\hline 4 & EOS & $\$ 3.891 .750 .370$ & $\$ 4,29$ \\
\hline 5 & Litecoin & $\$ 3.173 .099 .465$ & $\$ 52,36$ \\
\hline 6 & Bitcoin Cash & $\$ 2.764 .415 .114$ & $\$ 156,72$ \\
\hline 7 & Tether & $\$ 2.033 .896 .736$ & $\$ 1,01$ \\
\hline 8 & Stellar & $\$ 1.832 .296 .047$ & $\$ 0,095538$ \\
\hline 9 & TRON & $\$ 1.710 .738 .090$ & $\$ 0,025655$ \\
\hline 10 & Binance Coin & \$1.529.989.499 & $\$ 10,84$ \\
\hline
\end{tabular}

\section{Blok Zinciri (Blockchain)}

Blok zinciri işlemlerin bir ağda kaydedilmesini sağlayan ve paylaşılan hesap defteri aracılığıyla izlenmesini sağlayan bir platformdur. Blok zinciri teknolojisi muhasebe işlemlerinde bir sonraki adım olabilir. Firmalar yaptıkları işlemleri direk olarak kayıt altına alabilir ve dijital şifreleme ile muhasebeleşmiş kayıtları tutabilirler (Anderson 2016).

Bitcoin transfer işlemlerini içeren küresel hesap defteri, basit bir veri tabanıdır. 2009 yılından beri Bitcoin ile yapılan işlemlerin saklanmasını sağlamaktadır. Blok zinciri merkezi olmayan bir ağda, birbirinden bağımsız bilgisayarlarda saklandığından dolayı, hatalara karşı dirençlidir (Çarkacıŏlu 2016).

Kamuya açık şifrelenmesi sebebiyle, çifte harcama riskini ortadan kaldırır. Böylece her kullanıcı için bir adet özel şifrelenmiş anahtar (secret key) ve aracılar için de paylaşılan ortak bir anahtar (public key) atanır (Olleros ve Zhegu 2016). Her transferde Hash adı verilen, rastgele oluşmuş harf ve rakamlar dizini oluşturulur ve bu referans numarası blok zincirine eklenir. Her blok bir önceki bloğun özetini içerdiğinden, zincir halini alır. Herhangi bir bloğun değiştirilme teşebbüsünde geriye doğru tüm işlemlerin değişmesi gerekecektir ki bu durumda iş ispatı istendiğinden mümkün olamayacaktır (Prypto 2016).

Kullanılan işlemlerin koordinasyonu, kayıt tutması ve geri alınamaması en önemli özellikleridir. Bugüne kadar yapılmış ve yapılmakta olan tüm Bitcoin işlemlerini halka açık şekilde kaydetmek üzere madenciler işlem yaptıkça, blok zincirine kronolojik olarak bir halka daha eklenir. Blok zinciri ekonomiden başka, politik, sosyal ve bilimsel alanlarda kullanılabilir (Swan, 2015).

\section{Bitcoin ve Blok Zinciri Teknolojisinin Turizmde Kullanımı}

Blok zinciri genel anlamda Bitcoin ile ilişkili olmakla birlikte, kripto para birimlerinin çok ötesine geçmektedir. Bir ağ üzerinde dijital para transferleri, mal ve hizmet ödemeleri yapılabildiği gibi; otel veya uçuş rezervasyonu yapıp, sözleşme yapabilmeye olanak sağlar. Bunlara ilaveten kira sözleşmeleri yapılabilmekte ve kiralanan varlı̆̆ın takibi yapılabilmektedir. Kısaca blok zinciri teknolojisi ile mal veya hizmetin kayıt edilmesi, takibi, kiralanması mümkün olup, bilgiler ağa katılanlar ile paylaşılmakta ve veriler şifreleme anahtarları ile korunmaktadırlar (Dogru, Mody ve Leonardi 2018).

Bazı özel durumlar haricinde, blok zinciri yapısı kendi güvenliğini sağlar. Tek bir merkeze bağlı olmaması, saldırıların yapılmasını zorlaştırır. Ayrıca kontrolünün ele geçmesi de zordur. Yapılan bir işlemin engellenmesi, ağın tüm kontrolü tek kişide olmadıkça mümkün değildir. Engellenmek istenen işlem, er ya da geç bir madenci tarafından zincire eklenecektir (Taş ve Kiani 2018). Blok zincirinin iş dünyasında kullanımı ile ilgili dört önemli nokta bulunmaktadır; 


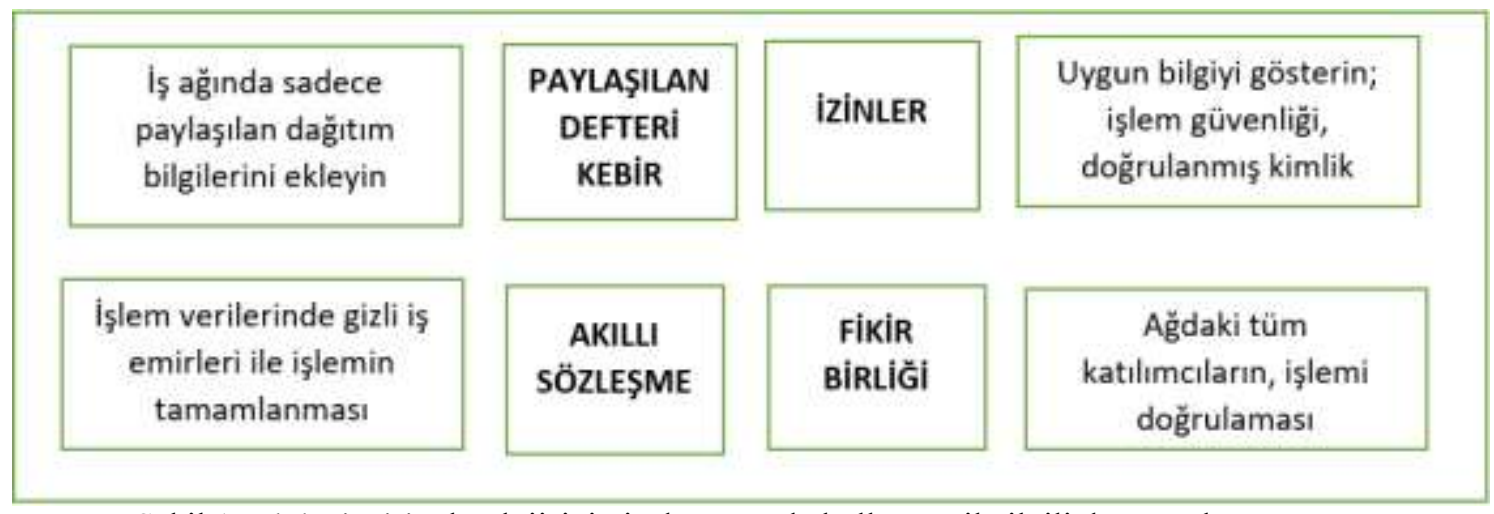

Şekil 1. Blok zinciri teknolojisinin iş dünyasında kullanımı ile ilgili dört ana kavram Kaynak: (Gupta 2017)

$>\quad$ Paylaşılan defterde, işlemlerin kayıtları bir blok zincirindeki tüm üyeler için mevcuttur. Özel bir izin ile sadece görüntüleme hakkına sahip olanlar verilere erişebilir.

$>\quad$ Blok zinciri içerisinde görüntüleme hakkına sahip olanların, özel bir izin ile kişiye özel kimliği vardır. Bu kimlik ve izin ile ağdaki işlemlere erişir. Böylece detayların sadece onay verilen kısmı katılımcılar tarafından görüntülenebilirken diğer detaylar sadece denetçiler tarafından görülebilir.

> Katılımcıların güvenilir olduğu bir ağda, işlemler katılımcıların fikir birliği ile doğrulanabilir.

$>\quad$ Akıllı sözleşmeler, bir işin yürütülmesini sağlayan kurallar bütünüdür. İşlemin tamamı ya da bir parçası blok zinciri üzerinde saklanır ve otomatik olarak yürütülür. Geleneksel sözleşmelere olan maliyetleri ve gecikmeleri azalttıkları gibi, güvenlik daha yüksektir. Örnek olarak, belirli bir süreden daha fazla rötar yapan uçuş ile ilgili, sigorta işlemlerini otomatikman başlatabilir (Gupta 2017).

Günümüzde küçük adalar ekonomilerini kripto para ve blok zinciri teknolojisini kullanarak düzenlemekteler. Morgan Stanley’e göre, küçük adaların günlük milyar doları bulan kripto para ticaret hacimleri bulunmakta (Kwok ve Koh 2018). Kripto para borsalarından Binance'in merkezini, Hong Kong'dan, Malta'ya taşıması ile kendisini "blok zinciri” adası olarak tanımlayan Malta'da doping etkisi yapmış ve yerini sağlamlaştırmıştır (Küçük 2018). Aruba ekonomisi büyük ölçüde turizme bağlı olup, tur operatörlerinden ziyade Ethereum zincirli The Widding Tree ile iş birliği yapmakta, havayolu, otel odası gibi rezervasyonlarda aracıları devreden çıkartmaktadır (Travers 2017). Barbados; etkili bir iletişim ve yetenekli iş gücü ile blok zinciri teknolojisini adada kullanmakta ve kripto para rezervlerini arttırarak, ekonomik faaliyetlerini çeşitlendirmektedir (Barbados 2018). Karayip Adaları (Anguilla, Antigua and Barbuda,Commonwealth of Dominica, Grenada, Montserrat,Saint Kitts and Nevis, Saint Lucia, Saint Vincent ve Grenadines), ekonomik koşullarını iyileştirmek için kripto paralara yöneldiler. Bankacılık hizmetleri yetersiz kaldığından, Bitcoin gibi kripto para birimleri kullanmakta ve kendi kripto para birimlerini yaratmaktadırlar. Özellikle Maria Kasırgasıyla harap olan Porto Riko, kripto para birimleri ile ekonomisini yeniden canlandırmaya çalışmaktadır. Geleneksel finansmanın başarısız olduğu ekonomilerde, kripto para birimleri devreye girmektedir (Callahan 2018). Mauritus adası ile Ethereum kuruluşu olan Consensys, ortaklık yaparak adayı teknolojik merkez haline getirmekte ve ülke ekonomisine katkı sağlamaktadır. Mauritus finansal seçenek olarak kullanılan bir ada olduğu gibi, "silikon koridoru" adlı yaklaşımı benimseyerek teknolojik atak yapmıştır. Blok zinciri teknolojisi ve özellikle Ethereum ticari büyüme sağlamıştır (Pollock 2017). Marshall Adaları, hükümet tarafından kabul edilen kripto para birimi Sovereign (SOV)'u borçlar, kamu harcamaları, vergi ve aidatlar için kullanılabileceğini bildirmiştir ve yasal ihale nedeniyle SOV, dünyada para olarak tanınmaktadır. SOV, arzı ve merkezi olmayan bir kripto para olmasına rağmen, yasal olarak para statüsünden yararlanmaktadır (Sov 2018). Vanuatu, turizmini teşvik ederek, ekonomik kalkınma sağlamak maksadıyla Volcano Coin çıkartmaya hazırlanıyor. Vanuatu vergi cenneti olan adalardan biridir ve turizmi gelişmiştir. Turizm, havacılık, oyun ve emlak alanında blok zinciri teknolojisini kullanarak ileriye dönük ekonomik büyüme hamleleri planlamaktadır (VanuatuNews 2018).

\subsection{Turizm Ve Ağırlama Sektöründe Kullanım Alternatifleri}

Turizm ve Ağırlama Sektöründe yer alan oteller, restoranlar, seyahat acentaları, hava ve kara taşıma firmaları tarafından hizmet kalitesini arttırmak, müşteri memnuniyetini sağlamak için blok zinciri teknolojisi kullanılabilir (Dogru ve diğ., 2018).

\subsubsection{Konukların Takibi}

Oteller, konuklarını uçak kalkış saati itibariyle takip edebilir, uçağın iniş saatine göre, otele varış süresini göz önüne alarak, misafir otele varmadan check in işlemleri için gerekli hazırlıkları yapabilir. Bu bekleme süresini azaltacak ve müşteri memnuniyetini arttıracaktır. Bilgi erişimi kişisel bilgilerin ihlaline sebebiyet verebileceğinden, konuğun paylaşılan bilgilerin derecesini belirlemesi gerekmektedir (Dogru ve diğ., 2018). 
Oteller ayrıca yolcuyu karşılayan araç firmasına ağ üzerinden erişim sağlayıp, yolcunun alınıp alınmadığı bilgisine ve varış saatine vakıf olabilecekleri gibi, otelden ayrılma zamanı geldiğinde yine aynı şekilde otel - araç - acenta koordinasyonu eş zamanlı olarak sağlanabilir. Böylece seyahat acentası yolcusu daha araçta iken, havayoluna ait check in işlemini gerçekleştirebilir ve yolcu direk olarak uçuşu için pasaport kontrolden geçebilir.

\subsubsection{Yiyeceklerin Takibi}

Gıda malzemeleri restoranlar için önem ihtiva eder ve tarladan itibaren gelişen tedarik zincirinin bir parçasıdır. Blok zinciri ile üretildiği andan tüketildiği ana kadar gıda malzemelerinin izlenmesi, restoranlar için kalite kontrol ve gida sağlığı açısından önem teşkil eder. Restoranlar müşterilerine de kullanılan malzemelerin kökenleri hakkında bilgi verebilirler. Bu şekilde müşterilerinde tükettikleri gıdalara karşı güveni artar (Dogru ve diğ., 2018).

Yiyecek sektöründe akıllı sözleşmeler yoluyla tedarikçiler ile anlaşma yapılabilir ve bu şekilde kullanılan malzemeler azaldıkça, blok zinciri sisteminde mevcut bulunan tedarikçiye, biten malzeme siparişi otomatikman verilebilir. Bu durumda satın alma takibi için ekstra personel ihtiyacı da azalacak ve hem malzeme ziyanı önlenecek hem de iş gücünden tasarruf edilecektir.

\subsubsection{Havayolu ve Otel Puanlama Sistemleri}

Sadakat programları özellikle turizm sektöründe hassas bir yapıdadır. Çünkü kazanılan puanlar araç, otel, ulaşım, yemek için farklı platformlardan kazanılır ve birbirine dönüşümlü olarak kullanımı zordur. blok zinciri sisteminde ise puanlar bir deftere kayıt edilip, gruplanabilir ve kazanım oldukça güncellenebilir (Kowalewski, McLaughlin, \& Hill, 2017).

Oteller ve havayolları blok zinciri dâhilinde sadakat programları oluşturabilir ve misafirlerine kullanımlarından dolayı puan ya da Bitcoin verebilir. Blok zinciri bir ağdaki tüm katılımcıların bir aracıya ihtiyaç duymadan işlem yapmasına olanak verdiğinden dolayı, sadakat programı içerisinde kazanılan puanlar ağ içinde bozdurulabilir ya da kullanılabilir (Kowalewski ve Simon, Will blockchain technology rewrite loyalty? (E.T 06.01.2019) 2016).

Araç kiralama ya da otel konaklamasından kazanılan Bitcoin ya da puan, bir restoranda veya havayolunda kullanılabilir; seyahat acentasına, havale masrafı olmadan ödeme yapılmasını sağlayabilir. Bitcoin ya da puan satılabilir, bozdurulabilir. Blok zinciri üzerindeki herhangi bir tedarikçiden mal veya hizmet almak için kullanılabilir.

\subsubsection{Dijital Kimlik}

Tüketiciler turizm işletmeleri hakkında bilgi edinebilmek için, yorum sitelerine girmektedirler. Çevrim içi tüketici incelemeleri giderek daha yaygınlaşmaktadır. Bununla birlikte güvenilirlikleri konusunda tereddütler bulunmaktadır (Filieri 2016). Merkezileştirilmiş otel, restoran gibi sistemler manipüle edilebilmekte ve yorumları istedikleri tarzda yönlendirebilmektedirler. Adil çevrim içi incelemeler yapılabilmesi için, kişisel bilgiler gizlenmek kaydıyla izlenebilir dijital kimlikler blok zinciri içerisinde oluşturulabilir. Verinin hangi kullanıcıdan geldiği, şifrelenmiş bir anahtar ile imzalanmasıyla tespit edilebildiğinden, kullanıcılar birden fazla yorum oluşturamazlar (Önder ve Treiblmaierb 2018).

Davidson, De Filippi, ve Potts, (2016) 'a göre; blok zinciri kimlik hırsızlı̆̆ için de bir çözüm yolu olabilir. Havaalanlarında, otel ve restoranlarda müşteriler güvenliği geçmek, kayıt yaptırabilmek veya alkol alabilmek için kimlik beyan etmek zorundadır. Bu esnada kimlik bilgilerini çaldırabilmektedirler. Kişisel bilgiler blok zinciri platformlarında saklanabilir ve sadece kontrol amaçlı olmak üzere, izinler verilebilir (Dogru ve diğ., 2018).

Seyahat acentalarında, yolcuların verilerinin üçüncü şahıslar ile paylaşılması etik değildir. Bazı durumlarda odaya giren ilk kişinin kimlik bilgileri alınabilmekte fakat yolcu talebi doğrultusunda ikinci kişi "no name" olarak geçebilmektedir. Bu şekilde bir uygulama ile özellikle odaya giren ikinci yolcunun kimlik bilgileri kayıt dişı tutulabilir. Sadece blok zinciri üzerinden izin verilen kodu girilebilir. Böylece otel ve acenta kayıtlarında kod olarak gözüken ikinci yolcu ismi, sadece güvenlik kuvvetlerine verilen raporda gözükebilir.

\subsubsection{Akıllı Sözleşmeler}

Ticari işlemleri yönetmeye yarayan akıllı sözleşmeler, bir işlemin tamamını ya da bir kısmını otomatikman yürütebilirler. Böylece zaman kaybı ve maliyetlerde azalmayı sağlarlar. Uçak otobüs ya da binek aracın, servis çıkış tarihlerinin kaydının blok zinciri üzerinden yapılması, aracın takibini kolaylaştırır. Böylece kullanılan araca güven artar. Ödemeler akıllı sözleşme ile takip edilebilir. İlaveten konuklar için akıllı sözleşmelerle işlem yapılabilir ve dijital kimlikleri ile giriş yapan yolcuların, check in işlemleri kısaltıldı̆̆ gibi, ödemeleri de sözleşme dâhilinde tahsil edilir (Gupta 2017).

Acentalar ve oteller arasında yapılan yıllık kontenjan anlaşmaları için akıllı sözleşmeler kullanılabilir ve vaat edilen tarihte acentaya ayrılan oda sayısı karşılığı ödeme, otomatikman işleme alınabilir. Bu şekilde oteller de sistem üzerinden blokajın otomatikman yapılması sebebiyle, oda sıkışıklığı yaşamayıp, short'a düşmeyeceklerdir. Aynı şekilde acentalar, yolcuların transferi esnasında kullanılan araç için akıllı sözleşmeler yapabilir ve blok zinciri üzerinden kaydı oluşturulmuş aracın, vaat edilen araç ile aynı olduğunun teyidini alabilir. Aracın konumu, güzergâhı, yolcu alıp bırakma noktaları ve zamanlama hakkında kesin bilgi sahibi olabilirler. 
Franchise sözleşmeleri akıllı kontratla yapıldığında, yönetim kuralları önceden belirlendiği şekilde, tarafların hakları güvenceye alınmış olur. Ayrıca akıllı sözleşmeler ile araç, ofis, daire kiralama işlemleri yapılabilir. AirBnb akıllı kontrat kullanarak, güvenlikle ilgili endişeleri de gidermiştir. (Dogru ve diğ., 2018). Slock.it ile akıllı anahtarlar geliştirilmiştir. blok zinciri dahilinde yapılmış akıllı kontrat süresi boyunca anahtar aktif olur ve kiralanan objeye giriş izni verir. Kontrat bitiminde anahtar pasif duruma geçer ve işlevsizleşir (Jentzsch 2018). Bu tarz bir anahtar özellikle araç kiralama sektöründe fayda sağlar. Aracın çalınmasına durumunda, anahtarın işlevsizleştirilmesi yöntemiyle güvenliği de sağlamış olur. Ayrıca otoban geçişleri veya trafik cezalarıda blok zinciri üzerinden takip edilebilir, akıllı kontrat dahilinde yolcunun hesabından otomatikman tahsil edilebilir.

\subsubsection{Para Transferleri}

Turizm ürünleri, paranın ülke içerisinde ve dışarısında birbirini önceden tanımayan kişiler arasında transfer edilmesini gerektirir. Güvenlik açısından aracıya ihtiyaç duyulur. Blok zinciri teknolojisi içinde kullanılan kripto paraların transferinde ise aracı gerekmez. Müşteri ile satıcı arasında direk iletişim ve kripto para aktarımı sağlanır (Önder ve Treiblmaierb 2018). Müşteri münferiden yada acenta vasıtasıyla otel rezervasyonu yaptığı zaman, odaya giriş tarihinden önce kripto para otelin hesabına geçer ve yolcu kur farkından etkilenmez. Aynı şekilde acenta tarafindan ayarlanan transferi, rehberlik hizmetleri, tur dahilindeki diğer hizmetler tek bir bütün olarak kripto parayla ödenir. Ödenen kripto para, paydaşlar arasında anlaşmaları dahilinde dağıtılır. Bu esnada banka komisyonu, eft - havale masrafı, kart ücreti, kart blokajı gibi ekstra masraflar aradan çıkartılmış olur.

\subsubsection{Seyahat Acentaları İçin Aracısız Ortam}

Tali seyahat acentaları için, global bir dağıtım sistemine sahip büyük bir acentanın parçası olma gereksinimi bulunmaktadır. Bu bayilik (franchise) anlaşması içinde belirli ücretler ödemeleri gerekmektedir (Önder ve Treiblmaierb 2018). Turizm genel olarak güç ilişkileri üzerinde kuruludur. Daha fazla yetkinliği olan, daha fazla fayda sağlar (Ford, Wang ve Vestal 2012). Blok zincirinin turizm sektörüne en önemli etkisi, aracısız ortam oluşturmasıdır. Online seyahat acentaları git gide daha tercih edilmektedir (Colombo ve Baggio 2017).

Havayolları biletlerini satabilmek için, öncelikle seyahat acentası olmak gerekmektedir. Seyahat acentası olabilmek için ise Kültür ve Turizm bakanlığına teminat vermek (Kültür Ve Turizm Bakanlığı 2018) ve Tursab'a giriş ücreti ödemek gerekir (Tursab, 2018). Daha sonra iç hat uçak bileti satabilmek için 10 bin Euro, hem iç hat hem de diş hat bilet satabilmek için havayoluna 30 bin Euro karşılığı teminat vermek gerekir (THY 2018). IATA üyesi olmak içinse 50 bin US Dolar karşılığ teminat mektubu verilmesi icap etmektedir (Tursab, 2017). Teminat mektuplarının verilebilmesi için ya nakit paranın bloke edilmesi gerekir ki buda kur farkları sebebiyle zarara sebebiyet verebilir yada bir mülk üzerinde ipotek koydurmak gerekir ki, ipotek masraflarıda ayrıca yekün tutar. İlaveten bankadan alınan teminat mektubunun da masrafi bulunmakta, işlem ücretleri ödenmesi gerekmektedir. Blok zinciri üzerinden kripto para birimleri ile teminat verilmesi durumunda ise hem aracı kurumlara ödenen masraflar ortadan kalkacak, hemde kur farklarından etkilenilmeyecektir.

\subsection{Turizm Sektöründe Kullanılan Altcoin'ler}

Altcoinler yaratıcıları tarafından belirli bir miktar olarak oluşturulmuştur. Kripto para (Coin) borsasında alınıp satılabilir, Bitcoin ile değiştirilebilir. Altcoinler ile sanal para transferi yapıldığında, işlem ücreti ödenir. Bununla birlikte işlem ücreti almayan altcoinlerde bulunmaktadır.

Aditus ile kripto para birimleri mülke dönüştürülür. Aditus ile ev alınabilir. Aditus ile lüks hizmet, seyahat deneyimi yaşanabilir, villa veya yat kiralanabilir, sanat satışları yapılabilir. Aditus servisleri kullanılırken, konsiyerj servis bedeli ödenir (CoinDigital 2018).

Seyahatler için yapılan para transfer ücretlerinin artması ve işlemlerin uzun sürmesi sebebiyle, sorunsuz kripto para transferi yapmaya olanak sağlayan BitAir ile işlem ücretleri düşer. Alıcılara rezervasyon yapma, uçak bileti alma, tur ve seyahat ile ilgili hizmetleri temin etme olanağı veren güvenli ve hızlı bir sistemdir. BTCA alıcı ve satıcılar arasında kullanılan dijital para birimidir ve BitAir ile daha fazla yolcu mal ve hizmet alabilir (IcoToken, 2019).

Briskpass, briskcoin denilen kendine özel kripto parası ile tüm dünyada toplu taşıma araçlarına ödeme yapmaya yarayan global bir sistemdir. Brisk cüzdan vasıtası ile toplu taşımaya ilaveten para transferlerinde, diğer kripto paralarda değişimde ve hizmet satın alma esnasındaki ödemelerde kullanılabilecektir (BriskPass 2017).

Travala, "neo blockchain" teknolojisini kullanan bir seyahat pazarıdır. Travala alıcı ve satıcı arasında iletişime izin verir ve komisyon uygulamaz. Travala hizmetlerini Neo ve Ava aracılığıyla sunması sebebiyle her şeyi dijital hale getirmiş ve rakiplerinden \%45 oranında daha düşük oranlarda fiyat sunar. Gemi seyahati, taksi hizmeti, uçak bileti dâhil olmak üzere taşıma ihtiyaçlarını karşılamayı amaçlar (Bitcoinexchangeguide 2018).

Bee Token ev sahibi ve konuk arasında iletişim sağlayan Ethereum tabanlı ev paylaşım platformdur. Rezervasyon ve giriş komisyonu yoktur, zincir üzerinden güvenli alışveriş imkânı sunar (BeeToken 2018). Beenest isimli merkezi olmayan ev paylaşım ağıdır. Ethereum tabanlı kripto para birimi olan Bee Token, kullanıcılar arasında güvenli para 
transferi yapılmasını sağlar. Güvenilir dijital imza ile Ethereum tabanlı blok zinciri platformu üzerinden işlem yapar. Merkezi olan sistemlerde, kiralama işlemleri için yüksek komisyonlar ödenirken, Bee Token ile yapılan akıllı sözleşmelerde, hiç komisyon alınmaz. Sadece "gas" adı verilen çok cüzi bir ücret tahsil eder (Bee 2018).

Trippki, otel ve misafiri arasında oluşturulmuş olan, rezervasyon ve ödül platformudur. Konuk kalışını tamamladıktan sonra, trip şeklinde bir geri bildirim alınır ve kripto para olarak ödül misafire tahsis edilir. Misafir bu kripto parayı harcayabilir veya alıp satabilir. Platformda kalınan oteller hakkında geri bildirim sağlanmış olur (TokenMarket 2018).

Casino Coin sanal oyun teknolojisi düşünülerek hazırlanmış, kullanıcıların ihtiyaçlarına göre özelleştirilmiştir. Hız ve güvenliği bir arada sunar (CasinoCoin 2013).

Gold poker coin, merkezi olmayan, açık kaynaklı bir kripto para birimi olup, aracıları devre dışı bırakır. Online poker oyunu için kullanılmakta olan blok zinciri tabanlı, çok düşük işlem ücreti uygulayan bir kripto paradır (Gold Poker 2018).

Big Mac Coin, McDonald's tarafından çıkartılmış olan uygulamanın mali değeri yoktur. Alınıp satılamaz, sadece puan toplamaya yarar ve karşıllı̆̆ında bir adet sandviç alınabilir (McDonalds 2018)

\section{Sonuç}

Literatürde Bitcoin hakkında yapılmış çalışmalar incelendiğinde, konu hakkında araştırmacıların farklı görüşleri olduğunu görülmüştür. Gültekin (2017) çalışmasında pazara yeni giren ürünlerde ödeme aracı olarak Bitcoin kullanılmasını, küçük işletmelerinde kripto para birimleri ile ödeme almalarını; Demir, ve diğ.(2018), ekonomik belirsizlik dönemlerinde Bitcoin'in risklerden korunma amacıyla kullanılabileceğini, Huang, ve diğg. (2018), Bitcoin ile aracısız işlemleri; Geiregat (2018), Bitcoin kullanıcılarının kimliklerini gizleyerek işlem yapabildiklerini; Yi, Zishuang ve Gang-Jin (2018), birbiriyle bağlantılı kripto paraların havalede büyük rol oynadığını; Smales (2018), Bitcoin'in istikrarsız bir yapıda olduğunu, işlem ücretinin fazla olduğunu, Pazar olgunlaşana kadar güvenilir olmadığını; Troster, ve diğ. (2018), Bitcoin'in aşırı oynak olup, risk taşıdığını; Easley, O'Hara ve Basu (2019), işlemlerde alınan ücretlerin yüksek olduğu; (Kliber, ve diğg. (2019), Bitcoin'in zayıf bir yatırım aracı olduğu; Saito ve Mitsuru (2019), Bitcoin'in yükselme eğilimi olması sebebiyle, kullanımdan ziyade yatırım aracı olduğunu; Shahzad, ve diğ. (2019), altın ve Bitcoin'in getiri oranlarını kıyaslayıp, Bitcoin'in avantajlı olduğunu; Alshamsi ve Andras (2019), tüketicilerin banka kartlarını, Bitcoin'e tercih ettiği; Luo, ve diğ. (2019), Bitcoin'in öngörülemeyen pozitif yada negatif sıçramaları olduğunu; Gözgör, ve diğ.(2019), rejim değişiklikleri ve ticari belirsizlik dönemlerinde Bitcoin'in olumsuz etkilendiğini bulmuştur.

Literatürde blok zinciri hakkında yapılan çalışmalar incelendiğinde Hughes, ve diğ.(2019), blok zincirinin sosyal ve ticari hayatta büyük ilgi gördüğünü, Bitcoin gibi kripto paraların kullanıcılar tarafından benimsendiğini ama blok zinciri kullanım hızının daha fazla olduğunu; (Kim 2018; Zheng, ve diğerleri 2019; Zhong, ve diğerleri 2019; Min 2019; Morkunas, Paschen ve Boon 2019) sistemin işleyişi ve güvenliği hakkında; Azzi, Kilany ve Sokhn (2019), grup ve münferit madencilik hakkında; (Behnke ve Janssen 2019; George, ve diğerleri 2019; Montecchi, Plangger ve Etter 2019), tedarik zinciri olarak, ürünlerin takibi için kullanılması hakkında çalışma yapmışlardır.

Bitcoin ve diğer kripto paralar pek çok alanda kullanılmaya devam ediyor. Blok zinciri teknolojisi günümüzde turizm sektöründe kullanılmaya başlandı. Tui grubu blok zinciri üzerinden iş süreçlerini idare ederek, otel envanterlerinin dağıtımını yapmakta ve IBM ile çalışmalarını geliştirmektedir. İsviçre merkezli Winding Tree tüketici ile seyahat tedarikçisini direk buluşturma amaçlı olarak blok zinciri sistemi oluşturmaktadır. Avustralya'da WebJet, Microsoft ile işbirliğine giderek havayolu kullanımı, araç kiralama ve otel rezervasyonları için blok zinciri platformuna dâhil olmuştur (Watkins 2017). Airbnb, Uber gibi şirketler tüketici ile direk temas halinde olmak için teknolojiden yaralanmaktadır (Önder ve Treiblmaierb 2018). Chipair, Expedia.com, More stamps Global, Bitcoin.Travel, A Class Limousine, Yachtbase.com, turizm sektöründe Bitcoin ile işlem yapan işletmelere dâhildir (Chokun, 2018; Moreau, 2019).

Türkiye'de hizmet sektöründe Bitcoin kabul eden yerler ise AvalonJet ile Rafine Gastro ve Batman - Van Kahvaltı isimli iki adet restoran ile sınırlıdır (F. L. CoinTurk 2018). Gelişen teknoloji ile gelecekte daha çok firmanın kripto para kullanımı ile blok zinciri platformuna dahil olması beklenmektedir. Konaklama işletmeleri blok zinciri ile müşterilerine direk ulaşabilmektedirler. Seyahat acentalarınında yeni yapılandırmalara gitmesi ve blok zinciri üzerinden tedarik zinciri oluşturarak, müsşterilerin talepleri doğrultusunda hizmet vermeleri gerekmektedir. Aracıların devre dışına çıkartılarak maliyetlerin düşürüldüğü bu sistem içerisinde, araştırılması gereken bir başka konu ise; taksitli olarak erken rezervasyon kampanyalarından yararlanan yolcuların, kripto paralar ile taksit seçeneklerinin oluşturulması yönünde olmasıdır.

Bitcoin ve blok zinciri kullanımı sunduğu faydaların yanında çeşitli riskleri de içermektedir. Bitcoin fiyatlarında aşırı dalgalanma, ödeme kabul eden firmaların karşılaştığı temel sorunlardan biridir. Ayrıca merkezi bir otoriteye sahip olmamak bir avantaj gibi görünmekle birlikte, kullanıcılar için dezavantaj da yaratmaktadır.

Blok zinciri kullanımı uzun vadede firmalar için işlem ve zaman maliyetlerini düşürse de, başlangıçta yüksek yatırım maliyetleri gerektirebilmektedir. Bu teknolojiye uyum sağlamak için firmaların dijital dönüşüm yapmaları gereklidir. Ayrıca alanın yeni olması nedeniyle yeterli sayıda ve donanımda insan kaynağı olmaması da bir sorun olarak görünmektedir. Kullanılan teknoloji yazılım hataları ve siber saldırılar tehlikesi ile de karşı karşıyadır. Bu durum firmalar kadar bireyler için de bir risk unsuru olarak değerlendirilebilir. Ayrıca yasal bir altyapının evrensel düzeyde oluşmaması nedeniyle, firmalar ve bireyler arasındaki olası sorunların nasıl aşılacağı da bir risk faktörü olarak ele alınmalıdır. Bitcoin ve blok zinciri sunduğu faydaların yanında bu tip riskleri de barındırmaktadır. 


\section{KAYNAKÇA}

Alshamsi, A., ve P. Andras. «User perception of Bitcoin usability and security across novice users.» International Journal of Human-Computer Studies, 2019: 126: 94-110.

Anderson, N. Blockchain Technology A game-changer in accounting? Deloitte, 2016.

Antonopoulos, Andreas M. Mastering Bitcoin: Programming the Open Blockchain. USA: O'Reilly Media, Inc, 2017.

Azzi, Rita, Rima Kilany, ve Maria Sokhn. «The power of a blockchain-based supply chain.» Computers \& Industrial Engineering, 2019.

Barbados. Blockchain Technology Could Help Barbados. 1304 2018. https://www.thedailyherald.sx/regional/75663blockchain-technology-could-help-barbados.

Bee. Bee Token The Future of the Decentralized Sharing Economy. 0611 2018. https://s3-us-west2.amazonaws.com/beenest-public/whitepaper/bee_whitepaper_v3.pdf.

BeeToken. Bee (E.T: 03.01.2019). 2018. https://www.beetoken.com/.

Behnke, Kay, ve M.F.H.A Janssen. «Boundary conditions for traceability in food supply chains using blockchain technology.» International Journal of Information Management, 2019.

Bilgin, Altay. Ayı ve Boğa Piyasası Ĕ̆ilimi Nedir? 04. 03. 2019. https://borsanasiloynanir.co/ayi-ve-boga-piyasasiegilimi-nedir/.

Bitcoinexchangeguide. Travala ICO (AVA Token): Blockchain Seyahat Rezervasyonu Cryptocurrency? 2018. https://bitcoinexchangeguide.com/travala-ico-ava-token/.

Böhme, Rainer, Nicolas Christin, Benjamin Edelman, ve Tyler Moore. «Bitcoin: Economics, Technology and Governance.» Journal of Economic Perspectives, 29 (2), 2015: 213-238.

BriskPass. Brisk Pass: Decentralizing Transportation. 2017. https://www.briskpass.com/\#about.

Callahan, Mary Ann. The rise of cryptocurrency in the Caribbean. $0803 \quad 2018$. https://www.caribbeannewsnow.com/2018/03/08/the-rise-of-cryptocurrency-in-the-caribbean/.

CasinoCoin. CasinoCoin (e.T: 03.01.2019). 2013. https://casinocoin.org/.

Chokun, Jonas. Who Accepts Bitcoins As Payment? List of Companies, Stores, Shops. 13092018. https://99bitcoins.com/who-accepts-bitcoins-payment-companies-stores-take-bitcoins/.

CoinDigital, Aditus. CoinDigital (E.T: 03.01.2019). 2507 2018. https://www.coindigital.com/what-is-aditus-adi/.

CoinMarketCap. CoinMarketCap. 07. 04. E.T.2019. https://coinmarketcap.com/coins/.

CoinMedya, LiteCoin. CoinMedya.com (E.T: 03.01.2019). 2002 2018. https://btc.coinmedya.com/litecoin-nedir-bitcoinile-arasindaki-farklar-nelerdir.html.

CoinTurk, Altcoin. CoinTurk Altcoin Nedir (E.T: 03.01.2019). 2510 2018. https://coin-turk.com/altcoin-nedir.

CoinTurk, Binance BNB. CoinTurk (E.T: 03.01.2019). 0411 2018. https://coin-turk.com/binance-coin-nedir-neredenalinir.

CoinTurk, Bitcoin. Bitcoin Nedir? 0611 2018. https://coin-turk.com/bitcoin-nedir.

CoinTurk, Etherum. CoinTurk (E.T: 03.01.2019). 2410 2018. https://coin-turk.com/inceleme-ethereum-nedir.

CoinTurk, Firma Listesi. Türkiye'de Bitcoin Kabul Eden Yerlerin Listesi. 2205 2018. https://coin-turk.com/turkiyedebitcoin-kabul-eden-yerlerin-listesi.

Colombo, Edoardo, ve R. Baggio. «Volume 8 : Knowledge Transfer To and Within Tourism Tourism Distribution Channels.» Bridging Tourism Theory and Practice içinde, yazan M. De Martino , M. Van Niekerk Editor: N.Scott, 289-301. Bingley UK: Emerald, 2017.

Çarkacıŏlu, Abdurrahman. Kripto-Para Bitcoin. E.T: 29.12.2018: Sermaye Piyasası Kurulu Araştırma Dairesi Araştırma Raporu, http: // www. spk. gov. tr / SiteApps / Yayin / YayinGoster / 1130 , 15, 2017, 2016.

Dai, W. b-money. 1998. http://www.weidai.com/bmoney.txt.

Demir, Ender, G. Gozgor, C. K. M. Lau, ve S.A. Vigne. «Does economic policy uncertainty predict the Bitcoin returns? An empirical investigation.» Finance Research Letters, 2018: 26: 145-149.

Dietz, M, T Olanrewaju, S Khanna, ve K Rajgopal. Cutting Through the FinTech Noise: Markers of Success, Imperatives For Banks (E.T: 29.12.2018). 02 2016. https://www.mckinsey.com/industries/financial-services/ourinsights/cutting-through-the-noise-around-financial-technology.

Dogru, Tarik, Makarand Mody, ve Christie Leonardi. «Blockchain Technology \& its Implications for the Hospitality Industry.» Boston University School Of Hospitality Administration, 2018: 1-13.

Döviz.com. Ethereum (ETH). 2302 2019. https://www.doviz.com/kripto-paralar/ethereum.

Easley, D., M. O'Hara, ve S. Basu. «From mining to markets: The evolution of bitcoin transaction fees.» Journal of Financial Economics, 2019.

Eğilmez, Mahfi. Kendime Yazılar. 2912 2018. http://www.mahfiegilmez.com/p/ekonomi-sozlugu.html.

Filieri, Raffaele. «What makes an online consumer review trustworthy?» Annals of Tourism Research, 58 , 2016 : $46-64$. 
Ford, Robert C, Youcheng Wang, ve Alex Vestal. «Power asymmetries in tourism distribution networks.» Annals of Tourism Research, 39 (2), 2012: 755-779.

Geiregat, Simon. «Cryptocurrencies are (smart) contracts.» Computer law \& security review, 2018: 34.5: $1144-1149$.

George, Reno Varghese, H.O. Harsh, P. Ray, ve A.K. Babu. «Food quality traceability prototype for restaurants using blockchain and food quality data index.» Journal of Cleaner Production, 2019: 240, 118021.

Gold Poker. Gold Poker Aces On Blockchain. 2018. http://www.gold-poker.com/gold_poker_whitepaper.pdf.

Gözgör, G., A.K. Tiwari, E. Demir, ve S. Akron. «The relationship between Bitcoin returns and trade policy uncertainty.» Finance Research Letters, 2019: 29: 75-82.

Graydon, Carter . What is Cryptocurrency? (Erişim 29.12.2018). Eylül 2014. https://www.ccn.com/cryptocurrency/.

Gupta, Manav. BlockChain For Dummies. NJ: A Wiley Brand. IBM Limited Edition, 2017.

Gültekin, Yaşar. «Turizm Endüstrisinde Alternatif Bir Ödeme Aracı Olarak Kripto Para Birimleri: Bitcoin.» Güncel Turizm Araştırmaları Dergisi, , 2017: 1.2: 96-113.

Huang, H., X. Chen, Q. Wu, X. Huang, ve J. Shen. «Bitcoin-based fair payments for outsourcing computations of fog devices.» Future Generation Computer Systems, 2018: 78: 850-858.

Hughes, A., A. Park, J. Kietzmann, ve C. Archer-Brown. «Beyond Bitcoin: What blockchain and distributed ledger technologies mean for firms.» Business Horizons, 2019: 62.3: 273-281.

IcoToken. BitAir Token: Yatırım Yapmaya Değer Mi? E.T: 03.01.2019. https://www.icotokennews.com/icos/bitair/.

Jentzsch, Christoph. Slock.it IoT Layer. 0806 2018. https://blog.slock.it/slock-it-iot-layer-f305601df963.

Kim, Song-Kyoo. «The trailer of blockchain governance game. .» arXiv preprint arXiv:1807.05581, 2018.

Kliber, Agata, P. Marszałek, I. Musiałkowska, ve K. Świerczyńska. «Bitcoin: Safe haven, hedge or diversifier? Perception of bitcoin in the context of a country's economic situation-A stochastic volatility approach.» Physica A: Statistical Mechanics and its Applications, 2019: 524: 246-257.

KoinMedya. KoinMedya. 21 04. E.T: 2019. https://koinmedya.com/2019/04/02/bitcoin-boga-sezonu/.

Kowalewski, Dan, ve Gregory Simon. Will blockchain technology rewrite loyalty? (E.T 06.01.2019). 08062016. http://www.hotelnewsnow.com/Articles/49347/Will-blockchain-technology-rewrite-loyalty.

Kowalewski, Dan, Jessica McLaughlin, ve Alex J. Hill. Blockchain Will Transform Customer Loyalty Programs (e.T: 06.01.2019). 1403 2017. https://hbr.org/2017/03/blockchain-will-transform-customer-loyalty-programs.

Küçük, Evrim. Türkiye, kripto para borsalarında ilk 5'te. 0705 2018. https://www.dunya.com/finans/haberler/turkiyekripto-para-borsalarinda-ilk-5te-haberi-414500.

Kültür Ve Turizm Bakanlığı. http://teftis.kulturturizm.gov.tr/. 1911 2018. http://teftis.kulturturizm.gov.tr/TR14578/seyahat-acentalari-yonetmeligi.html.

Kwok, A. O, ve S.G Koh. «Is blockchain technology a watershed for tourism development?» Current Issues in Tourism, 2018: 1-6.

Luo, M., V.E. Kontosakos, A.A. Pantelous, ve J. Zhou. «Cryptocurrencies: Dust in the wind?» Physica A: Statistical Mechanics and its Applications, 2019: 525: 1063-1079.

McDonalds. $\quad$ www.mcdonalds.com.tr $\quad$ (E.T: 03.01 .2019$).$ https://www.mcdonalds.com.tr/kurumsal/kampanyalar/big-mac-coin-kampanyasi.

Min, Hokey. «Blockchain technology for enhancing supply chain resilience.» Business Horizons, 2019: 62.1: 35-45.

Montecchi, Matteo, Kirk Plangger, ve Michael Etter. «It's real, trust me! Establishing supply chain provenance using blockchain.» Business Horizons, 2019: 62.3: 283-293.

Moreau, Elise. 15 Major Retailers and Services That Accept Bitcoin. 0201 2019. https://www.lifewire.com/big-sitesthat-accept-bitcoin-payments-3485965.

Morkunas, Vida J., Jeannette Paschen, ve Edward Boon. «How blockchain technologies impact your business model.» Business Horizons, 2019: 62.3: 295-306.

Nakamoto, Satoshi. «Bitcoin: A Peer-to-Peer Electronic Cash System.» https://bitcoin.org/bitcoin.pdf (E.T:22.01.2019), 2008.

Olleros, Xavier F, ve Majlinda Zhegu. Research Handbook on Digital Transformations. Northampton USA: Edward Elgar Publishing, 2016.

Önder, İrem, ve Horst Treiblmaierb. «Blockchain and tourism: Three research propositions.» Annals of Tourism Research, 2018: 1-3.

Peters, Rene. Gulden Coin (NLG) Nedir? (E.T: 03.01.2019). 09 Aralık 2017. https://captainaltcoin.com/what-is-guldencoin/.

Pollock, Darryn . "Ethereum Island” Mauritius Craves To Become Blockchain Paradise. 13072017. https://cointelegraph.com/news/ethereum-island-mauritius-craves-to-become-blockchain-paradise.

Prypto. Bitcoin For Dummies. New Jersey: John Wiley \& Sons, Inc, 2016. 
Rotman, Sarah . Bitcoin Versus Electronic Money . 01 2014. https://openknowledge.worldbank.org/handle/10986/18418. Saito, Kenji, ve Iwamura Mitsuru . «How to make a digital currency on a blockchain stable.» Future Generation Computer Systems , 2019: 100: 58-69.

Shahzad, S.J.H., E. Bouri, D. Roubaud, ve L. Kristoufek. «Safe haven, hedge and diversification for G7 stock markets: Gold versus bitcoin.» Economic Modelling, 2019.

Smales, Lee A. «Bitcoin as a safe haven: Is it even worth considering?» Finance Research Letters, 2018.

Sov. SOV. 2018. https://www.sov.global/.

Swan, Melanie. Blockchain: Blueprint for a New Economy. USA: O'Reilly Media, Inc., 2015 First Edition.

Taş, Oğuzhan, ve Farzad Kiani. «Blok Zinciri Teknolojisine Yapılan Saldırılar Üzerine bir İnceleme.» Bilişim Teknolojileri Dergisi, 11 (4), 2018: 368-382.

THY. THY Acente Portal / yurt içi . 1911 2018. https://ap.thy.com/agencyportal/p/yurtici-yetkili-yolcu-bileti-sat-sacenteligi-basvuru-kosullar-ve-istenilen-belgeler.

TokenMarket. TokenMarket (E.T: 03.01.2019). 2018. https://tokenmarket.net/blockchain/ethereum/assets/trippki/.

Travers, Julia. Ethereum'un Blockchain'i Aruba'nın Seyahat Sektörünü Geri Kazanmasına Yardımcı Olabilir mi? 0612 2017. https://btcmanager.com/can-ethereums-blockchain-help-aruba-reclaim-travel-industry/.

Troster, Victor, A.K. Tiwari, M. Shahbaz, ve D.N. Macedo. «Bitcoin returns and risk: A general GARCH and GAS analysis.» Finance Research Letters, 2018.

Tursab. Tursab'dan Haberler. 2402 2017. https://www.tursab.org.tr/tr/tursabdan-haberler/baskandan/tursab-iatatoplantisinda-alinan-kararlar_15846.html.

—. Üye Giriş Aidat Ödentisi (E.T: 08.01.2019). 09.03 2018. 03 https://www.tursab.org.tr/tr/tursabdanhaberler/bilgilendirme-amaclidir2018-yili-uye-giris-aidat-odentisi_17195.html.

Üzer, Betül. «Sanal Para Birimleri (Uzmanlık Yeterlilik Tezi).» Türkiye Cumhuriyet Merkez Bankası Ödeme Sistemleri Genel Müdürlüğ̈̈, 2017.

VanuatuNews. Vanuatu Plans Tu Issue Volcano Coin To Promote Local Tourism And Economic Development. 2018. https://www.vilatimes.com/2018/06/11/vanuatu-plan-to-issue-volcano-coin-to-promote-local-tourism-andeconomic-development/.

Watkins, Ed. The Definitive Guide to Hotel Blockchain Technology (E.T:08.01.2019). 22092017. https://www.duettocloud.com/library/definitive-guide-hotel-blockchain-technology.

Yi, Shuyue, Yu Zishuang, ve Wang Gang-Jin. «Volatility connectedness in the cryptocurrency market: Is Bitcoin a dominant cryptocurrency?» International Review of Financial Analysis, 2018: 60: 98-114.

Yıldırım, Fatih. «Kripto Paralar, Blok Zinciri Teknolojisi ve Uluslararası İlişkilere Muhtemel Etkileri.» Medeniyet Araştırmaları Dergisi, 2 (4), 2015: 81-97.

Zheng, H., Q. Wu, J. Xie, Z. Guan, B. Qin, ve Z. Gu. «An Organization-friendly Blockchain System.» Computers \& Security, 101598, 2019.

Zhong, L., Q. Wu, J. Xie, Z. Guan, ve B. Qin. «A secure large-scale instant payment system based on blockchain.» Computers \& Security, 2019: 84: 349-364. 